\title{
Fabrication and Optical Characterization of Palm Fiber Reinforced Acrylonitrile Butadiene Styrene Based Composites: Band Gap Studies
} \author{
Farid Ahmed ${ }^{1}$ \\ ${ }^{1}$ Department of Physics, Jahangirnagar University, Dhaka, Bangladesh \\ ${ }^{2}$ Department of Physics, Saga University, Saga, Japan \\ ${ }^{3} \mathrm{PP}$ and PDC, Bangladesh Council of Scientific and Industrial Research, Dhaka, Bangladesh \\ Email: rahmanmahbubur@ymail.com, 17634903@edu.cc.saga-u.ac.jp
}

Budrun Neher', Md. Mahbubur Rahman Bhuiyan ${ }^{1,2}$, Humayun Kabir'1, Md. Abdul Gafur³,

How to cite this paper: Neher, B., Bhuiyan, Md.M.R., Kabir, H., Gafur, Md.A. and Ahmed, F. (2018) Fabrication and Optical Characterization of Palm Fiber Reinforced Acrylonitrile Butadiene Styrene Based Composites: Band Gap Studies. Materials Sciences and Applications, 9, 246-257.

https://doi.org/10.4236/msa.2018.92016

Received: November 27, 2017

Accepted: February 4, 2018

Published: February 7, 2018

Copyright $\odot 2018$ by authors and Scientific Research Publishing Inc. This work is licensed under the Creative Commons Attribution International License (CC BY 4.0).

http://creativecommons.org/licenses/by/4.0/

\begin{abstract}
The composite materials are replacing the conventional materials, owing to their excellent properties. The developments of new materials are on the anvil and are thriving day by day. Natural fiber composites such as palm fiber (PF) polymer composites became more enchanting because of their high specific strength, low weight and biodegradability. Mixing of natural fiber like PF with acrylonitrile butadiene styrene (ABS) polymer is finding increased applications. In this work, PF reinforced ABS composites PF-ABS was fabricated by Injection Moulding Machine. The effect of UV-Visible radiation on PF-ABS composites was studied by means of ultraviolet-visible spectroscopy in the wavelength $200-1000 \mathrm{~nm}$ at room temperature. The present investigation shows that the addition of palm fiber modifies the absorption property of the materials. The absorption ability is maximal for 10\% PF-ABS composites while minimal for $20 \%$ PF-ABS composites in the visible region of the spectrum. Optical constant like direct band gap energy, Urbach energy and Steepness parameter were determined using absorbance data. The values of direct energy band gap, Urbach energy as well as Steepness parameter were found to be in the range $2.6-3.9 \mathrm{eV}, 0.40-0.85 \mathrm{eV}$ and $0.03-0.06$, respectively. It was observed that the value of direct band gap energy as well as Urbach energy is higher while the value of Steepness parameter is lower for PF-ABS composites with $10 \%$ palm fiber.
\end{abstract}

\section{Keywords}

Palm Fiber, UV-Visible Spectroscopy, Band Gap, Bio-Degradable 


\section{Introduction}

Natural fiber (NF) as reinforcing agent in polymer composites has generated much attention in recent years for making low cost engineering materials. Manufacturing industries like automotive, construction and packaging company are searching new materials which can replace conventional non-renewable reinforcing materials such as glass fiber due to pressure of new environmental legislation and consumer demand [1] [2] [3] [4]. Good specific strengths and modulus, economical viability, low density, reduced tool wear, enhanced energy recovery, and reduced thermal and respiratory irritation and good biodegradability make natural plant fiber more reliable candidate over traditional glass fiber [5] [6] [7] [8] [9]. Due to excellent thermo-mechanical properties, biodegradability, low density and non-toxicity, composite materials reinforced with natural fiber are extensively used in many fields, namely civil, industrial, military, space craft, and biomedical sector [10] [11] [12] [13]. Natural fibers as like as jute, palm coir, sisal, pineapple, banana, kenaf, ramie, bamboo, and saw dust are used as reinforcement in different polymer, such as polypropylene, polyethylene, unsaturated polyester, acrylonitrile butadiene styrene, PVC, etc to prepare fiber composite [14]-[24]. Palm fiber is one of specific interest among these fibers since palm fiber (Palmyra Palm) is produced substantially all over Bangladesh. Acrylonitrile-butadiene-styrene (ABS) is an engineering thermoplastic terpolymer which is prepared by polymerizing styrene and acrylonitrile in the presence of poly butadiene. ABS has very good mechanical properties, especially high impact resistance and it is used between $-20^{\circ} \mathrm{C}$ and $80^{\circ} \mathrm{C}$ as its mechanical properties vary with temperature [25] [26] [27]. The natural fiber's properties mainly depend on the chemical composition of the fiber. The optical behaviour of the composites can be altered by addition of natural fiber [28] [29]. Natural fiber reinforced polymer composites are also used in optical devices. The optical behaviour of polymer materials can be customized by the addition of some filler, which depends upon its reactivity with the host polymer matrix [30] [31]. A large number of experiments on optical properties of composites have been performed all over the world using Ultraviolet-Visible (UV-Vis) spectroscopy. K. Al-Ammar [32] investigated the optical properties of PMMA-CrCl ${ }_{2}$ composites. They observed that the absorbance increased with the rise of the concentration of $\mathrm{CrCl}_{2}$. The optical and mechanical properties for PVA- $\mathrm{AgCO}_{3}$ composites were studied by B. H. Rabee [33]. They reported that the absorption coefficient increased while indirect allowed and forbidden energy gap decreased with increase of the weight percentage of silver carbonate content. S. Hadi et al. [34] analyzed the optical characteristics of polyvinyl alcohol and lithium fluoride composites and reported that the absorbance decreased while coefficient of absorption, extinction coefficient, and refractive index along with real and imaginary parts of dielectric constant increased with the addition lithium fluoride content. M. Ali et al. prepared and investigated the optical properties of polyvinyl alcohol- and poly-acrylic acid-fiber of wheat composites and obtained re- 
sults indicated that the absorbance of the composites improved while energy band gap reduced with addition of the fiber of wheat concentrations [35]. Optical properties of polymer composites reinforced by natural materials were investigated by A. S. Jasim [36]. The absorbance was found to be decreased with the increasing of wavelength for all types of prepared composites, while increased with the increasing of palm fiber ratio. Keeping these facts in mind, the palm fiber was taken reinforcing agent in this study. This is because palm fiber is available in Bangladesh and is anticipated that it will offer composites having fascinating optical properties. Although citations on the preparation and characterizations of PF-ABS composites are carried out but the amount of studies are very limited and require more insightful analysis. As such this paper seeks a better understanding on the estimation of band-energy sharpness, Urbach-energy and steepness parameter of PF-ABS composites using the UV-Vis absorbance spectral distribution. The physical, structural, morphological, mechanical, electrical and thermal properties of these PF-ABS composites have been cited in our more recent study [25] [26] [27].

\section{Experimental}

\subsection{Raw Materials Collection}

Palm leaves were collected from ten different aged trees from Burura, Comilla, Bangladesh. Hammering was done at the dividing ends of the middle rigid part of the palm leaves. Rigid part of the leaves was kept in underwater for 20 days to rotten. Rotten materials were cleaned and fiber were then separated, dried under sun light and kept at around $100^{\circ} \mathrm{C}$ for one day for removal of moisture. ABS polymer was purchased from scientific shop old Dhaka, Bangladesh.

\subsection{Preparation of Composite}

Palm fiber was sliced into $1-2 \mathrm{~mm}$ in sized. ABS and small palm fiber were dried for 1 day at $50^{\circ} \mathrm{C}$ using a dryer. Fined palm fiber and ABS polymer placed into the injection moulding machine. The mixture of palm fiber and ABS polymer was heated at around $150^{\circ} \mathrm{C}$ inside the injection molded machine (IMM). The molten mixture became composite and came out of the IMM. This composite was transferred into different shape of die for different test. Composites samples (with 5\%, 10\% and 20\% palm fiber content) were prepared along with pure ABS polymer ( $0 \%$ palm fiber) to accomplish this research.

\subsection{Characterization and Properties}

UV-visible spectroscopy of ABS and composites (containing $1-2 \mathrm{~mm}$ long fibers as filler) were performed in absorption mode using Shimadzu UV-1601 spectrometer (Shimadzu Corporation, Tokyo, Japan) in the wavelength range 200 to $1000 \mathrm{~nm}$ at room temperature. The composite sample which is a rectangular bar was in the dimension of $105.5 \mathrm{~mm} \times 10.5 \mathrm{~mm}$. Before performing test, the samples were kept in the incubator (Memmart, Model: ICP400) at $50^{\circ} \mathrm{C}$ for 
one day, then removed and cooled in the desiccator. The optical absorption was measured with reference to air.

\section{Result and Discussion}

The UV-visible spectroscopy is an important powerful experimental technique for identification of various optical transitions in the materials. The optical energy gaps, the allowed direct and indirect transitions and forbidden transitions of optically active substances can be determined from the UV-visible spectroscopy studied for the potential applications such as light guide materials, optical fibers, optical coating to inhibit corrosion, etc.

\subsection{Fiber Loading Effect on Absorbance of PF-ABS Composites}

The effect of palm fiber loading on the absorbance with respect to wavelength is shown in Figure 1. It is found from Figure 1 that the absorbance of pure ABS rises with the increase of wavelength and becomes higher in the visible region (400 - $700 \mathrm{~nm}$ ). This indicates that the low energy light absorbs by the pure ABS polymer. It is also observed that the absorption of pure ABS is comparatively lower than that of the PF-ABS composites. The maximum absorbance within PF-ABS composites is found with $10 \% \mathrm{PF}$. The increase of absorbance with the rise of fiber content in composites is also found by K. Al-Ammar et al. [32].

In the case of PF-ABS composites, at around $200 \mathrm{~nm}$ absorbance was around 2.8 unit (for 10\% PF-ABS composites). After $190 \mathrm{~nm}$ absorbance decrease up to $400 \mathrm{~nm}$ (initial point of visible region). After $400 \mathrm{~nm}$, absorbance of PF-ABS composites exponentially increased up to $700 \mathrm{~nm}$. Absorbance is highest at 700 $\mathrm{nm}$ for all PF-ABS composites. This reveals that in the UV region with the decrease of energy (with increase of wave length) absorption decreased which means PF-ABS composites transmit UV-ray rapidly. But in visible region with

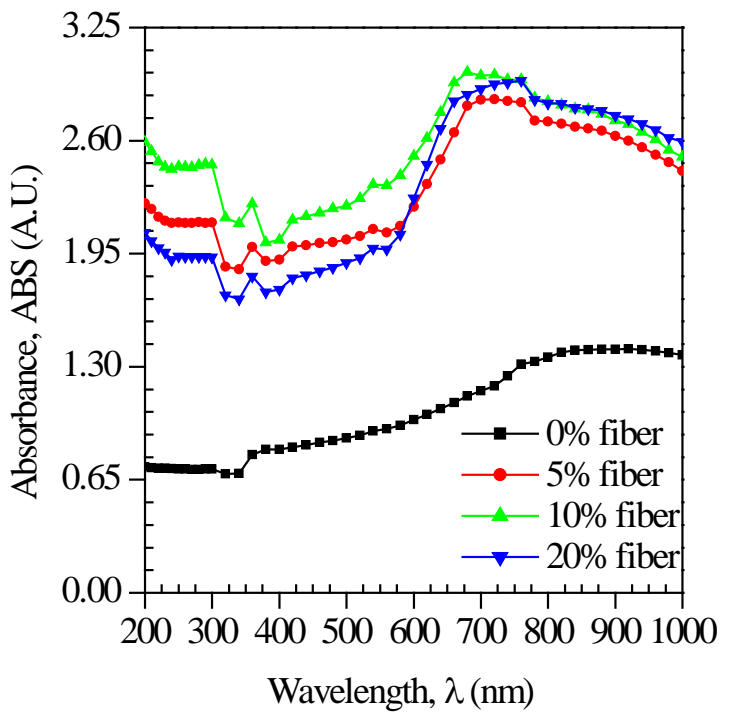

Figure 1. Variation of absorbance with wavelength at different fiber contents. 
the decrease of energy (wave length increased) absorbance increased meaning that low amount of visible light is transmitted. However, after visible region (after $700 \mathrm{~nm}$ ), with decreasing energy absorption decreases while transmittance increases. The average absorbance of pure ABS and PF-ABS composites with respect to wt (\%) of palm fiber in composites is summarized in Table 1.

\subsection{Effect of Fiber Loading on Optical Band Gap in Composites}

Coefficient of absorption ( $\alpha$ ) is defined as the ability of a material to absorb the light of given wavelength and can be calculated by the Equation (1),

$$
\alpha=2.303 \frac{A}{t}
$$

where $A$ and $t$ are absorption and thickness of the material respectively.

The absorption coefficient at various photon energies for pure ABS and PF-ABS composites is plotted in Figure 2. The absorption coefficient for pure ABS is lower than that of PF-ABS composites. Palm fiber addition in PF-ABS composite increases absorption coefficient of all composites. Among the three different composites, the absorption coefficient for $10 \%$ PF-ABS composites is greater than that of $5 \%$ as well as $20 \%$ PF-ABS composites. Similar result was found by S. Hadi et al. experiment [34].

Table 1. Average absorbance of pure ABS, PF-ABS composites.

\begin{tabular}{cc}
\hline Fiber content in composites (\%) & Average absorbance \\
\hline $0 \%$ & 1.157 \\
$5 \%$ & 2.393 \\
$10 \%$ & 2.552 \\
$20 \%$ & 2.447 \\
\hline
\end{tabular}

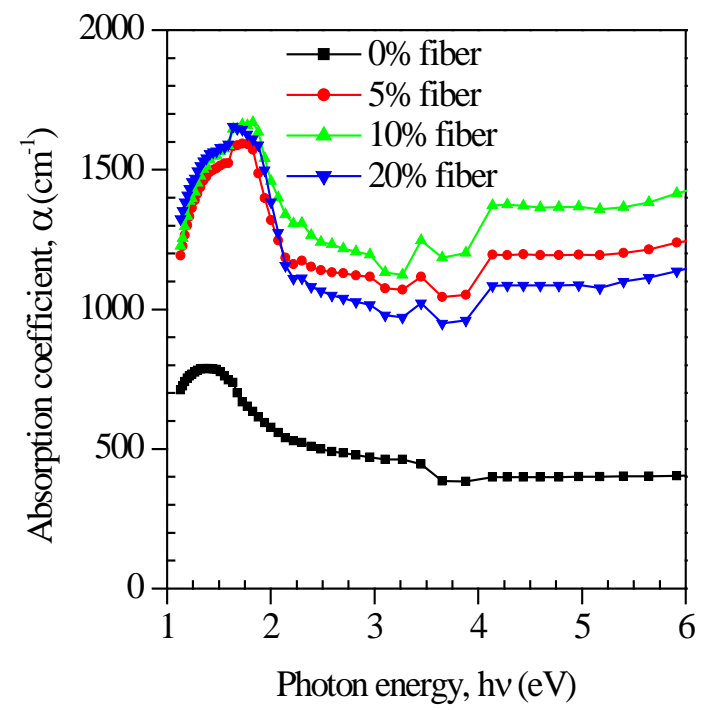

Figure 2. Effect of absorption coefficient on fiber contents of PF-ABS composite at different photon energy. 
The optical absorption coefficient was used to determine the band gap energy of the solid polymer composites, using the Tauc relation in the following form [37]:

$$
\alpha h \vartheta=R\left(h \vartheta-E_{g}\right)^{S}
$$

where, $R$ is a constant not connected to the energy, $E_{g}$ the optical energy band gap and $S$ is parameter that describes the nature of band transition. The value of $S=1 / 2$ and 2 correspond to direct and indirect allowed transitions, respectively while that of $3 / 2$ and 3 indicate direct and indirect forbidden transitions, respectively. The $E_{g}$ can be estimated from extrapolation of the straight-line part of the $(\alpha h v)^{1 / s}$ against $h v$ graph to $h v=0$. The direct band gap energy $\left(E_{d g}\right)$ and indirect band gap $\left(E_{i g}\right)$ was computed from the plots $(\alpha h v)^{2}$ against $h v$ and $(\alpha h v)^{1 / 2}$ against $h v$, respectively which are shown in Figure 3 and Figure 4. From Figure 4 , it can be found that the investigated samples have no indirect band gap. The

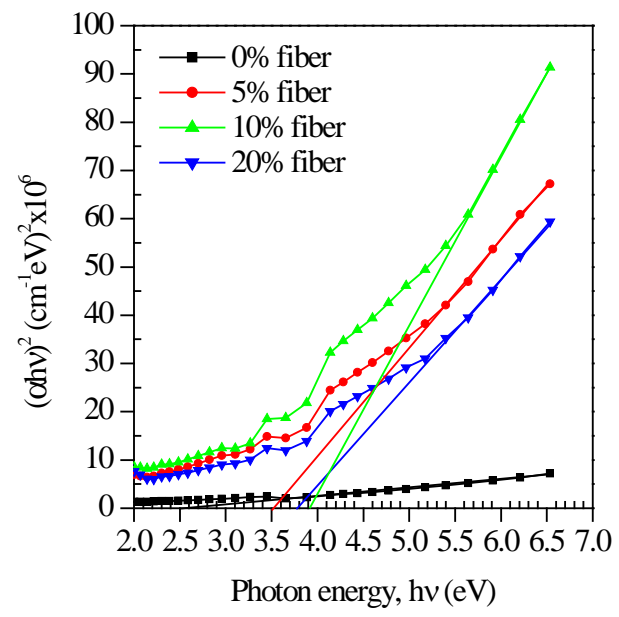

Figure 3. The plot of $(\alpha h v)^{2}$ vs $h v$ for different fiber contents of PF-ABS composite at various photon energy.

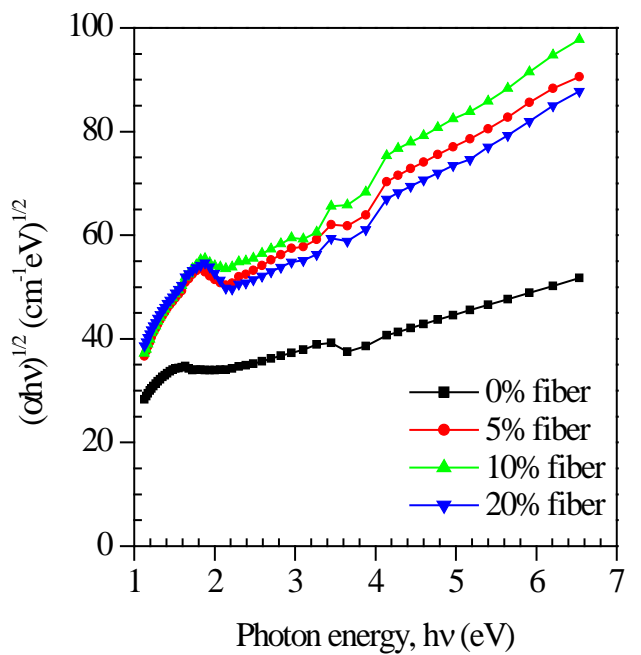

Figure 4. The plot of $(\alpha h v)^{1 / 2}$ vs $h v$ for different fiber contents of PF-ABS composite at various photon energy. 
obtained values of $E_{d g}$, are noted in Table 2. The direct band gap energy values for pure ABS, PF-ABS composites are in the range of $2.6-3.9 \mathrm{eV}$. It is observed that direct band gap energy is maximum for $10 \%$ PF-ABS composites while minimum for pure ABS.

\subsection{Urbach Energy and Steepness Parameters of PF-ABS Composite}

Generally, the spectral reliance of $\alpha$ is investigated in the region of the photon energies under energy gap of the materials. This region is termed as Urbach spectral tail which indicates the gradient of the exponential edge. The relation between $\alpha$ and photon energy $(E)$ in the Urbach spectral tail region can be expressed as [38],

$$
\alpha=\alpha_{0} \exp \left(\frac{E}{E_{u}}\right)
$$

where $a_{0}, E_{u}$ are a constant and Urbach energy respectively. The $E_{u}$ can be worked out as the tail of the exponential absorption edge or as the breadth of the tails of localized states. The graph obtained by plotting $\ln \alpha$ against $h v$ should be linear whose gradient gives the value of $E_{u}$. The $\ln \alpha$ vs $h v$ plots for pure ABS and PF-ABS composites are represented in Figure 5 and the estimated values of $E_{u}$ are recorded in Table 3. It is observed that the value of $E_{u}$, is maximum for $10 \%$

Table 2. Direct band gap energy of pure ABS, PF-ABS composites.

\begin{tabular}{cc}
\hline PF-ABS composites (\% of palm fiber) & Direct Band Gap (eV) \\
Pure ABS (0\% fiber) & 2.6 \\
PF-ABS composites with $5 \%$ fiber & 3.5 \\
PF-ABS composites with 10\% fiber & 3.9 \\
PF-ABS composites with 20\% fiber & 3.8 \\
\hline
\end{tabular}

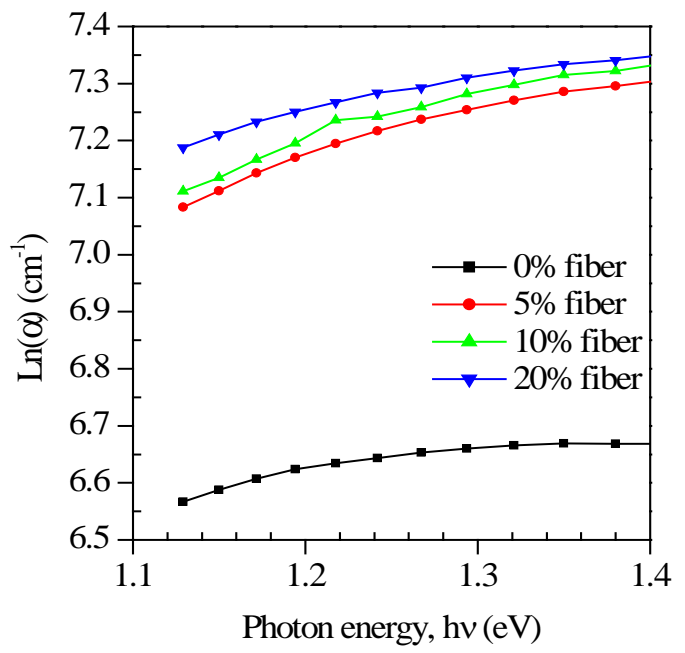

Figure 5. The plot of $\operatorname{Ln}(\alpha)$ vs $h v$ for different fiber contents of PF-ABS composite at various photon energy. 
PF-ABS composites and minimum for pure ABS. The steepness parameter $(\sigma)$ that represents the expansion of the optical absorption end because of interaction of electron phonon or exciton-phonon [39], could be computed with the following relation,

$$
\sigma=\frac{k T}{E_{u}}
$$

where $k$ and $T$ are Boltzmann constant and absolute temperature, respectively. In calculation of $\sigma$ in this study, the value of $T$ was $300 \mathrm{~K}$. The calculated values of $\sigma$ are tabulated in Table 3. It can be noticed that the value of steepness parameter is maximal for pure ABS while minimum for $5 \%$ as well as $10 \%$ PF-ABS composites.

\subsection{Extinction Co-Efficient of PF-ABS Composite}

The value of $\alpha$ as well as $\lambda$ can be used to find the values of extinction coefficient, $K$ by using the simple equation [39],

$$
K=\frac{\alpha \lambda}{4 \pi}
$$

The variation of $K$ for pure ABS and PF-ABS composites with respect to wavelength of the UV-visible light spectrum is shown in Figure 6. In each case of

Table 3. Urbach energy and Steepness parameter for pure ABS, PF-ABS composites.

\begin{tabular}{ccc}
\hline Wt (\%) of palm fiber in composites & Urbach energy, $E_{u}(\mathrm{eV})$ & Steepness parameter, $\sigma$ \\
\hline Pure ABS (0\% fiber) & 0.40 & 0.06 \\
PF-ABS composites with 5\% fiber & 0.84 & 0.03 \\
PF-ABS composites with 10\% fiber & 0.85 & 0.03 \\
PF-ABS composites with 20\% fiber & 0.61 & 0.05 \\
\hline
\end{tabular}

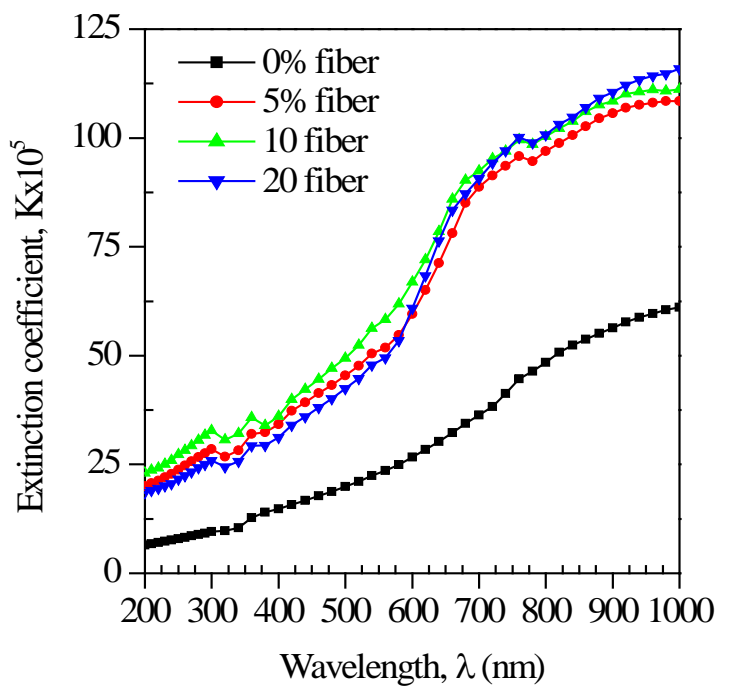

Figure 6. Variation of extinction coefficient with wavelength for pure ABS and PF-ABS composites. 
$5 \%, 10 \%$ and $20 \%$ PF-ABS composite samples, total ten samples from two age groups were taken for extinction co-efficient calculation. The extinction co-efficient of PF-ABS composites is much higher than the pure ABS. The extinction co-efficient increased slightly with the addition of palm fiber in PF-ABS composite. Similar result was found in PVA-LiF composite by S. Hadi et al. [34].

\section{Conclusion}

The UV-visible properties of pure ABS as well as PF-ABS composites were investigated using UV-visible spectrometer. The result indicates that addition of palm fiber modifies absorption property of composite materials. The absorption ability is enhanced for $10 \%$ PF-ABS composites. The direct band gap energy varies at $2.6-3.9 \mathrm{eV}$. The highest direct band gap energy is obtained for $10 \%$ PF-ABS composites. The values of Urbach energy and Steepness parameter vary at $0.40-0.85 \mathrm{eV}$ and $0.03-0.06 \mathrm{eV}$, respectively. Maximum Urbach energy is observed while minimum Steepness parameter is for $10 \%$ PF-ABS composites. The extinction coefficient of PF-ABS composites is greater than that of pure ABS polymer matrix.

\section{References}

[1] Dhakal, H.N., Zhang, Z.Y. and Richardson, M.O.W. (2007) Effect of Water Absorption on the Mechanical Properties of Hemp Fiber Reinforced Unsaturated Polyester Composites. Composites Science and Technology, 67, 1674-1683. https://doi.org/10.1016/j.compscitech.2006.06.019

[2] Verma, C.S. and Chariar, V.M. (2012) Development of Layered Laminate Bamboo Composite and Their Mechanical Properties. Composites Part B: Engineering, 43, 1063-1069. https://doi.org/10.1016/j.compositesb.2011.11.065

[3] Pickering, K.L., Aruan Efendy, M.G. and Le, T.M. (2016) A Review of Recent Developments in Natural Fiber Composites and Their Mechanical Performance. Composites Part A: Applied Science and Manufacturing, 83, 98-112. https://doi.org/10.1016/j.compositesa.2015.08.038

[4] Jahan, A., Rahman, M.M., Kabir, H., Kabir, M.A., Ahmed, F., Hossain, M.A. and Gafur, M.A. (2012) Comparative Study of Physical and Elastic Properties of Jute and Glass Fiber Reinforced LDPE Composites. International Journal of Scientific \& Technology Research, 1, 68-72.

[5] Islam, M.M., Kabir, M.A., Kabir, H., Ahmed, F. and Gafur, M.A. (2015) Mechanical and Thermal Properties of Sand Reinforced Polyester Resin Composite. International Letters of Chemistry, Physics and Astronomy, 56, 123-127.

[6] Biswas, S., Shahinur, S., Hasan, M. and Ahsan, Q. (2015) Physical, Mechanical and Thermal Properties of Jute and Bamboo Fiber Reinforced Unidirectional Epoxy Composites. Procedia Engineering, 105, 933-939.

https://doi.org/10.1016/j.proeng.2015.05.118

[7] Saba, N., Paridah, M.T., Abdan, K. and Ibrahim, N.A. (2016) Dynamic Mechanical Properties of Oil Palm Nano Filler/Kenaf/Epoxy Hybrid Nanocomposites. Construction and Building Materials, 124, 133-138.

https://doi.org/10.1016/j.conbuildmat.2016.07.059 
[8] Saba, N., Paridah, M.T., Abdan, K. and Ibrahim, N.A. (2016) Effect of Oil Palm Nano Filler on Mechanical and Morphological Properties of Kenaf Reinforced Epoxy Composites. Construction and Building Materials, 123, 15-26. https://doi.org/10.1016/j.conbuildmat.2016.06.131

[9] Lu, T., Jiang, M., Jiang, Z., Hui, D., Wang, Z. and Zhou, Z. (2013) Effect of Surface Modification of Bamboo Cellulose Fibers on Mechanical Properties of Cellulose/Epoxy Composites. Composites Part B: Engineering, 51, 28-34. https://doi.org/10.1016/j.compositesb.2013.02.031

[10] Khan, R.A., Khan, M.A., Zaman, H.U., Noor, N., Huq, T., Khan, A., Dey, K., Sarker, B., Saha, S., Rahman, M.M., Saha, M. and Gafur, M.A. (2010) Study on the Mechanical and Thermal Properties of Jute-Reinforced Methyl Acrylate Grafted PET Composites. Polymer-Plastic Technology and Engineering, 49, 373-380. https://doi.org/10.1080/03602550903532125

[11] Pathania, D., Singh, D. and Sharma, D. (2010) Electrical Properties of Natural Fiber Graft Copolymer Reinforced Phenol Formaldehyde Composites. Optoelectronics and Advanced Materials-Rapid Communications, 4, 1048-1051.

[12] Goulart, S.A.S., Oliveira, T.A., Teixeira, A., Miléo, P.C. and Mulinari, D.R. (2011) Mechanical Behaviour of Polypropylene Reinforced Palm Fibers Composites. Procedia Engineering, 10, 2034-2039. https://doi.org/10.1016/j.proeng.2011.04.337

[13] El-Tayeb, N.S.M. (2008) A Study on the Potential of Sugarcane Fibers/Polyester Composite for Tribological Applications. Wear, 265, 223-235. https://doi.org/10.1016/j.wear.2007.10.006

[14] Ramesh, M., Palanikumar, K. and Hemachandra Reddy, K. (2013) Mechanical Property Evaluation of Sisal-Jute-Glass Fiber Reinforced Polyester Composites. Composites: Part B, 48, 1-9. https://doi.org/10.1016/j.compositesb.2012.12.004

[15] Fardausy, A., Kabir, M.A., Kabir, H., Rahman, M.M., Begam, K., Ahmed, F., Hossain, M.A. and Gafur, M.A. (2012) Study of Physical, Mechanical and Thermal Properties of Unidirectional Jute Fiber Reinforced PVC Film Composites. International Journal of Advanced Research in Engineering and Technology, 3, 267-274.

[16] Liu, H., Wu, Q., Han, G., Yao, F., Kojima, Y. and Suzuki, S. (2008) Compatibilizing and Toughening Bamboo Flour-Filled HDPE Composites: Mechanical Properties and Morphologies. Composites. Part A, 39, 1891-1900. https://doi.org/10.1016/j.compositesa.2008.09.011

[17] Islam, M.M., Kabir, H., Gafur, M.A., Bhuiyan, M.M.R., Kabir, M.A., Qadir, M.R. and Ahmed, F. (2015) Study on Physio-Mechanical Properties of Rice Husk Ash Polyester Resin Composite. International Letters of Chemistry, Physics and Astronomy, 53, 95-105.

[18] Saba, N., Paridah, M.T., Abdan, K. and Ibrahim, N.A. (2016) Physical, Structural and Thermomechanical Properties of Oil Palm Nano Filler/Kenaf/Epoxy Hybrid Nanocomposites. Materials Chemistry and Physics, 184, 64-71. https://doi.org/10.1016/j.matchemphys.2016.09.026

[19] Brugnago, R.J., Satyanarayana, K.G., Wypych, F. and Ramos, L.P. (2011) The Effect of Steam Explosion on the Production of Sugarcane Bagasse/Polyester Composites. Composites: Part A, 42, 364-370. https://doi.org/10.1016/j.compositesa.2010.12.009

[20] Kabir, H., Gafur, M.A., Ahmed, F., Begum, F. and Qadir, M.R. (2014) Investigation of Physical and Mechanical Properties of Bamboo Fiber and PVC Foam Sheet Composites. Universal Journal of Materials Science, 2, 119-124.

[21] Su, S.K. and Wu, C.S. (2010) The Processing and Characterization of Polyester/Natural Fiber Composites. Polymer-Plastics Technology and Engineering, 49, 
1022-1029. https://doi.org/10.1080/03602559.2010.482083

[22] Liao, M., Yang, Y. and Hamada, H. (2016) Mechanical Performance of Glass Woven Fabric Composite: Effect of Different Surface Treatment Agents. Composites. Part $B$, 86, 17-26. https://doi.org/10.1016/j.compositesb.2015.08.084

[23] Khan, Z., Yousif, B.F. and Islam, M.M. (2017) Fracture Behaviour of Bamboo Fiber Reinforced Epoxy Composites. Composites: Part B, 116, 186-199. https://doi.org/10.1016/j.compositesb.2017.02.015

[24] Verma, C.S. and Chariar, V.M. (2013) Stiffness and Strength Analysis of Four Layered Laminate Bamboo Composite at Macroscopic Scale. Composites: Part B, 45, 369-376. https://doi.org/10.1016/j.compositesb.2012.07.048

[25] Neher, B., Bhuiyan, M.M.R., Kabir, H., Qadir, M.R., Gafur, M.A. and Ahmed, F. (2014) Study of Mechanical and Physical Properties of Palm Fiber Reinforced Acrylonitrile Butadiene Styrene Composite. Journal of Materials Sciences and Applications, 5, 39-45.

[26] Neher, B., Bhuiyan, M.M.R., Kabir, H., Gafur, M.A., Qadir, M.R. and Ahmed, F. (2016) Thermal Properties of Palm Fiber and Palm Fiber-Reinforced ABS Composite. Journal of Thermal Analysis and Calorimetry, 124, 1281-1289. https://doi.org/10.1007/s10973-016-5341-x

[27] Neher, B., Bhuiyan, M.M.R., Gafur, M.A., Kabir, H., Hoque, M.A., Bashar, M.S., Ahmed, F. and Hossain, M.A. (2015) Study of the Electric Properties of Palm Fiber-Reinforced Acrylonitrile Butadiene Styrene Composites. Journal of Reinforced Plastics and Composites, 34, 1253-1260. https://doi.org/10.1177/0731684415591067

[28] Jahan, A., Rahman, M.M., Kabir, H., Kabir, M.A., Ahmed, F., Hossain, M.A. and Gafur, M.A. (2013) Electrical and Thermal Properties of Jute and Glass Fiber Reinforced LDPE Composites. International Journal of Basics \& Applied Sciences, 1, 482-490.

[29] Afroze, S., Kabir, H., Rahman, M.M., Kabir, M.A., Ahmed, F., Hossain, M.A. and Gafur, M.A. (2012) Physical, Optical and Thermal Properties of Graphite and Talc Filler Reinforced Polypropylene (PP) Composites. International Journal of Advanced Scientific and Technical Research, 5, 40-49.

[30] Yang, Y., Zhao, D., Xu, J., Dong, Y., Ma, Y., Qin, X., Fujiwara, K., Suzuki, E., Furukawa, T., Takai, Y. and Hamada, H. (2017) Mechanical and Optical Properties of Silk Fabric/Glass Fiber Mat Composites: An Artistic Application of Composites. Textile Research Journal.

[31] Afroze, S., Kabir, H., Rahman, M.M., Kabir, M.A., Ahmed, F., Hossain, M.A. and Gafur, M.A. (2012) Elastic and Electrical Properties of Graphite and Talc Filler Reinforced Polypropylene (PP) Composites. International Journal of Basic \& Applied Sciences, 12, 13-16.

[32] Al-Ammar, K., Hashim, A. and Husaien, M. (2013) Synthesis and Study of Optical Properties of (PMMA-CrCl 2 ) Composites. Chemical and Materials Engineering, 1, 85-87.

[33] Rabee, B.H. (2011) Study of Optical and Mechanical Properties for (PVA-AgCO $)$ Composites. European Journal of Scientific Research, 57, 583-591.

[34] Hadi, S., Hashim, A. and Jewad, A. (2011) Optical Properties of PVA-LiF Composites. Australian Journal of Basic and Applied Sciences, 5, 2192-2195.

[35] Ali, M., Hashim, A., Nayyef, S., Nasih, B. and Lafta, F. (2014) Structural and Optical Properties of (PVA-PAA-FW) Composites. International Journal of Science and Research (IJSR), 3, 280-283. 
[36] Jasim, A.S. (2016) Preparation and Optical Characterization of Polymer Composites Reinforced by Natural Materials. Journal of Al-Nahrain University, 19, 91-97. https://doi.org/10.22401/JNUS.19.1.11

[37] Tauc, J., Menth, A. and Wood, D. (1970) Optical and Magnetic Investigations of the Localized States in Semiconducting Glasses. Physical Review Letters, 25, 749-752. https://doi.org/10.1103/PhysRevLett.25.749

[38] Urbach, F. (1953) The Long-Wavelength Edge of Photographic Sensitivity and Electronic Absorption of Solids. Franz Urbach Physical Review, 92, 1324-1330.

[39] Mahr, H. (1962) Ultraviolet Absorption of KI Diluted in KCl Crystals. Physical Review, 125, 1510-1515. https://doi.org/10.1103/PhysRev.125.1510 